\title{
ANALISIS KEMAMPUAN KOGNITIF MATEMATIKA MATERI OPERASI HITUNG PECAHAN MENGGUNAKAN VIDEO PEMBELAJARAN MATEMATIKA SISTEM DARING DI KELAS V SEKOLAH DASAR
}

\author{
Yantoro, Suci Hayati, Latifatul Ulya
}

Surel: Yan.unja@gmail.com

\begin{abstract}
This study aims to determine the cognitive ability of mathematics in the fraction count operation material using the online mathematics learning video system in class $V$ of Elementary School No. 34 / I Lotus. The test was conducted to determine the students' cognitive abilities. There were 14 students out of 28 students who collected the test results. Based on the data analysis, it was found that the cognitive abilities of students in the high category were 6 students, while in the low category were 8 students. The results of the students 'high cognitive mathematics abilities were $50 \%$ and the students' low cognitive abilities were 50\%. The results of observations from this study concluded that the students' lack of activeness during online learning using video lessons. This can be seen from the number of students who collected test results as many as 14 students out of 28 students. It can be concluded that students' cognitive mathematical abilities during online learning have different abilities. This can be seen from the level of student ability from the results of the tests carried out.
\end{abstract}

Keywords: Cognitive Ability, Mathematics, Count Fraction Operations

\begin{abstract}
ABSTRAK
Penelitian ini bertujuan untuk mengetahui kemampuan kognitif matematika materi operasi hitung pecahan menggunakan video pembelajaran matematika sistem daring di kelas V Sekolah Dasar Negeri No. 34/I Teratai. Tes dilakukan untuk mengetahui kemampuan kognitif siswa. Terdapat sebanyak 14 siswa dari 28 siswa yang mengumpulkan hasil tes. Berdasarkan analisis data, diperoleh kemampuan kognitif siswa dalam kategori tinggi sebanyak 6 siswa, sedangkan kategori rendah sebanyak 8 orang siswa. Hasil kemampuan kognitif matematika siswa yang tinggi sebanyak 50\% dan kognitif siswa yang rendah sebanyak 50\%. Hasil observasi dari penelitian ini disimpulkan bahwa kurangnya keaktifan siswa selama mengikuti pembelajaran daring menggunakan video pembelajaran. Hal ini dapat dilihat dari jumlah siswa yang mengumpulkan hasil tes hanyak sebanyak 14 siswa dari 28 siswa. Dapat disimpulkan bahwa kemampuan kognitif matematika siswa selama pembelajaran daring memiliki kemampuan yang berbeda-beda. Hal ini dapat dilihat dari tingkatan kemampuan siswa dari hasil tes yang dilakukan.
\end{abstract}

Kata Kunci: Kemampuan Kognitif, Matematika, Operasi Hitung Pecahan

\section{PENDAHULUAN}

Pada pendidikan formal, salah satu mata pelajaran yang selalu dijumpai dalam setiap jenjang pendidikan adalah matematika, ini membuktikan bahwa matematika 
merupakan elemen penting dalam pendidikan. Mengenai tujuan pembelajaran matematika yakni: (a) memahami konsep matematika, mendeskripsikan bagaimana keterkaitan antar konsep matematika dan menerapkan konsep atau logaritma secara efisien, luwes, akurat, dan tepat dalam memecahkan masalah, (b) menalar pola sifat dari matematika, mengembangkan atau mamanipulasi matematika dalam menyusun argumen, merumuskan bukti, atau mendeskripsikan argumen dan pernyataan matematika, (c) memecahkan masalah matematika yang meliputi kemampuan memahami masalah, menyusun model penyelesaian matematika, menyelesaikan model matematika, dan memberi solusi yang tepat, dan (d) mengkomunikasikan argumen atau gagasan dengan diagram, tabel, simbol atau media lainnya agar dapat memperjelas permasalahan atau keadaan (Depdiknas, 2014: 11).

Salah satu tujuan pembelajaran matematika adalah melatih cara berpikir, dan bernalar dalam menarik kesimpulan, materi matematika dan kemampuan kognitif matematika merupakan dua hal yang tidak dapat dipisahkan, yaitu materi matematika dipahami melalui kemampuan kognitif, dan kemampuan kognitif diasah dan dilatihkan melalui belajar materi matematika, sehingga kemapuan kognitif matematika sangat penting dan dibutuhkan dalam mempelajari matematika.

Matematika merupakan suatu ilmu yang menjadi mata pelajaran di setiap jenjang pendidikan yang ada di Indonesia. Hampir dalam setiap aktivitas sehari-hari tanpa disadari pasti menggunakan ilmu matematika. Menurut Susanto (2014:184) "bidang studi matematika diperlukan untuk proses perhitungan dan proses berpikir yang sangat di butuhkan orang dalam menyelesaikan berbagai masalah". Oleh karena itu, matematika menjadi mata pelajaran yang paling penting untuk di kuasai setiap orang di mulai dari anak kecil hingga dewasa.

Di dalam pembelajaran matematika banyak sekali materi yang diajarkan kepada siswa, salah satunya yaitu operasi hitung pecahan. Dalam mempelajari operasi hitung pecahan melalui penggunaan video pembelajaran banyak siswa yang tidak memahami penyampaian materi yang diajarakan melalui video pembelajaran tersebut. Video pembelajaran ini ialah pembelajaran yang dilakukan dengan sistem daring.

Sistem pembelajaran daring merupakan upaya belajar dari rumah atau studi from home, dengan cara tidak bertatap muka secara langsung. Tetapi, menggunakan platform yang dapat membantu proses belajar mengajar yang dilakukan meskipun pembelajaran jarak jauh. Salah satu cara yang dilakukan oleh guru yaitu menggunakan video.

Video pembelajaran ialah suatu media yang disusun secara sistematis dengan berpedoman kepada kurikulum yang berlaku dan dalam mengembangkannya mengaplikasikan prinsip-prinsip pembelajaran sehingga 
program tersebut memungkinkan peserta didik mencermati materi pelajaran secara lebih mudah dan menarik. Di masa pandemi saat ini pembelajaran dengan cara menggunakan video tentunya bisa membuat peserta didik merasakan adanya kemudahan dikarenakan di jelaskan dengan cara yang lebih menarik. Apalagi pada proses pembelajaran sistem daring ini peserta didik belajar di rumah, agar masing-masing dari mereka bisa memahaminya.

Salah satu mata pelajaran yang dianggap sulit bagi peserta didik tingkat Sekolah Dasar itu adalah mata pelajaran matematika, pada mata pelajaran matematika tingkat Sekolah Dasar kelas V, ada kompetensi indikator yang harus dicapai, salah satu kompetensi yang harus dicapai oleh peserta didik itu adalah menyelesaikan masalah yang berkaitan dengan materi operasi hitung pecahan pada mata pelajaran matematika kelas V Sekolah Dasar.

Pembelajaran matematika

sangatlah penting untuk kemampuan kognitif siswa. Kognitif berasal dari kata cognition yang berarti pengertian atau mengerti. Maksud pengertian dalam area kognitif ini adalah perolah, penataan, dan penggunaan pengetahuan. (Indrijati, 2016: 44). Sedangkan menurut Basri (2018: 1) kognitif merupakan suatu kemampuan yang mengedepankan keterampilan berbasis otak dan di perlukan untuk melakukan tugas apapun mulai dari sederhana hingga kompleks. Maka dapat disimpulkan bahwa kognitif merupakan keterampilan yang berbasis otak dan digunakan untuk menyelesaikan tugas apapun secara bertahap.

Berdasarkan hasil wawancara yang peneliti lakukan di SD Negeri No.34/I Teratai. Pada pandemi saat ini, proses pembelajaran telah dilakukan secara daring dengan menggunakan aplikasi WhatsApp. Kemudian, memberikan materi pembelajaran matematika dengan mengirimkan video yang telah dibuatkan oleh guru. Dari hasil wawancara dengan guru kelas V B bahwasanya kognitif matematika siswa dalam melaksanakan pembelajaran secara daring melalui penggunaan video pembelajaran matematika ini berbagai macam tingkatan pengetahuan kognitif yaitu dari tingkat C-1, C-2, C-3, C-4, C-5, dan C-6.

Dari berbagai tingkatan kognitif tersebut ada 18 siswa dari 28 siswa dikelas $\mathrm{V} \quad \mathrm{B}$ mengalami hambatan dalam pembelajaran daring dengan penggunaan video pembelajaran yaitu hambatan dalam jaringan, memori gawai, serta masih ada siswa yang belum memiliki gawai.

Tujuan penelitian ini adalah untuk mendeskripsikan bagaimana kemampuan kognitif matematika materi operasi hitung pecahan menggunakan video pembelajaran matematika secara daring di kelas $\mathrm{V}$ Sekolah Dasar Negeri No.34/I Teratai. 
Yantoro, Suci Hayati, Latifatul Ulya : Analisis Kemampuan ...

\section{METODE PENELITIAN}

Penelitian ini menggunakan pendekatan kualitatif, yang bertujuan untuk mengumpulkan data-data dan mendeskripsikan fakta atau fenomena yang terjadi saat penelitian. Kemudian penelitian ini mendeskripsikan hasil dari kemampuan kognitif matematika materi operasi hitung pecahan menggunakan video pembelajaran matematika sistem daring di kelas $\mathrm{V}$ sekolah dasar. Jenis penelitian ini adalah penelitian studi kasus. Penelitian ini dimulai dengan permasalahan yang didapatkan dilapangan.

\section{HASIL PENELITIAN DAN} PEMBAHASAN

Pada bagian ini akan dideskripsikan kemampuan kognitif matematika materi operasi hitung pecahan menggunakan video pembelajaran matematika sistem daring di kelas V B Sekolah Dasar Negeri No. 34/I Teratai tahun ajaran 2020/2021.

Data pada variabel kemampuan kognitif siswa menggunakan instrumen yang berbentuk tes. Instrumen tes, diisi oleh 14 responden yang memiliki 5 butir pertanyaan. Setiap butir pertanyaan memiliki tingkatan kognitif dimulai dari Lots hingga Hots.

Tabel 1. Daftar Nilai Tes

\begin{tabular}{|c|c|c|c|c|c|c|c|c|}
\hline \multirow{2}{*}{ No } & \multirow{2}{*}{ Nama } & \multicolumn{5}{|c|}{ Nomor Soal } & \multirow{2}{*}{ Skor } & \multirow{2}{*}{ Kriteria } \\
\hline & & 1 & 2 & 3 & 4 & 5 & & \\
\hline 1 & $\mathrm{RF}$ & 1 & 4 & 1 & 2 & 2 & 10 & Sedang \\
\hline 2 & NY & 4 & 4 & 4 & 4 & 4 & 20 & Tinggi \\
\hline 3 & $\mathrm{AG}$ & 0 & 4 & 4 & 4 & 4 & 16 & Tinggi \\
\hline 4 & RH & 0 & 4 & 4 & 4 & 4 & 16 & Tinggi \\
\hline 5 & EL & 1 & 3 & 3 & 2 & 4 & 13 & Sedang \\
\hline 6 & $\mathrm{AZ}$ & 4 & 4 & 4 & 4 & 4 & 16 & Tinggi \\
\hline 7 & NB & 2 & 4 & 4 & 4 & 4 & 18 & Tinggi \\
\hline 8 & $\mathrm{IZ}$ & 2 & 2 & 1 & 0 & 2 & 7 & Rendah \\
\hline 9 & $\mathrm{AR}$ & 0 & 0 & 4 & 0 & 0 & 4 & Rendah \\
\hline 10 & SLB & 4 & 4 & 0 & 0 & 0 & 8 & Rendah \\
\hline 11 & $\mathrm{RS}$ & 4 & 4 & 1 & 1 & 4 & 14 & Sedang \\
\hline 12 & FR & 0 & 3 & 2 & 2 & 0 & 7 & Rendah \\
\hline 13 & IZT & 0 & 4 & 0 & 2 & 4 & 10 & Sedang \\
\hline 14 & MRV & 0 & 4 & 4 & 4 & 4 & 16 & Tinggi \\
\hline
\end{tabular}

Keterangan :

Skor 0-7= Rendah

Skor 8-14= Sedang

Skor $15-20=$ Tinggi

Berdasarkan tabel tersebut disimpulkan bahwa terdapat 2 orang disimpulkan bahwa terdapat siswa yang pemahaman kognitif 
masih rendah, terdapat 4 orang siswa yang pemahaman kognitif masih sedang dan terdapat 8 orang siswa yang pemahaman kognitif tinggi.

\section{Pembahasan}

Pemahaman kognitif siswa dalam pembelajaran matematika menggunakan video pembelajaran selama pembelajaran daring masih belum terlalu baik. Hal ini dikarenakan kurangnya kemampuan dan keaktifan siswa selama belajar dirumah. Menurut Honggowiyono (2015:5) kognitif atau bisa disebut intelek adalah kemampuan berpikir yang dimiliki oleh setiap individu dalam melakukan sesuatu atau memecahkan suatu permasalahan.

Peran orang tua sebagai fasilitator dianggap masih belum mampu membimbing siswa selama pembelajaran daring. Karena selama pembelajaran daring siswa masih belum memberikan hasil yang maksimal. Latar belakang pendidikan orang tua juga mempengaruhi pelaksanaan belajar yang dilakukan siswa. Oleh sebab itu, materi yang tidak dipahami oleh siswa tidak sepenuhnya mampu dijelaskan kembali oleh siswa. Pembelajaran matematika menjadi hal yang sulit untuk dipahami oleh siswa. Siswa membutuhkan bimbingan yang lebih dalam memahami pembelajaran matematika.

Berdasarkan hasil observasi, wawancara dan tes terhadap siswa kelas V B pemahaman kognitif siswa masih belum baik karena siswa memiliki tingkat pemahaman yang berbeda-beda. Pemahaman kognitif siswa tersebut ada yang pemahaman kognitifnya tinggi, sedang dan rendah. Siswa yang memiliki pemahaman kognitif yang tinggi mampu menyelesaikan soal dengan baik dan benar dan siswa tersebut menjawab serta menjelaskan pertanyaan yang diajukan oleh peneliti. Untuk siswa yang pemahaman kognitifnya sedang itu masih kurang tepat dalam menyelesaikan soal dengan baik, dan kurang tepat dalam menjawab dan menjelaskan pertanyaan dari peneliti. Sedangkan pemahaman kognitif siswa yang rendah tidak mampu menyelesaikan soal dengan baik, dan tidak bisa menjawab serta menjelaskan pertanyaan dari peneliti.

Kemampuan kognitif siswa selama pembelajaran daring sangat berbeda dengan pembelajaran tatap muka. Hasil belajar siswa yang berbeda dengan pembelajaran tatap muka menjadi pertimbangan bagi guru dalam menentukan nilai siswa. Siswa yang biasanya memiliki kemampuan kognitif yang rendah ketika pembelajaran daring memiliki nilai yang sangat tinggi. Sebaliknya, siswa yang memiliki kemampuan kognitif tinggi memiliki nilai yang biasa saja selama pembelajaran daring.

Pembelajaran daring merupakan suatu terobosan untuk melakukan proses belajar mengajar secara efektif dan efisien untuk melayani kebutuhan peserta didik dalam hal pendidikan (Dewi, 2017). Akan tetapi, selama pelaksanaan pembelajaran daring di 
kelas V B belum dapat berjalan dengan baik. Hal ini disebabkan karena pembelajaran yang dilakukan secara daring baru pertama kali diterapkan dan butuh penyesuaian terlebih dahulu agar sistem pembelajaran daring dapat berjalan dengan baik.

Berdasarkan hasil temuan yang didapatkan terdapat kemampuan siswa dalam mengerjakan tugas operasi hitung pecahan yang berbedabeda. Seperti yang dipaparkan oleh peneliti bahwa siswa kelas V B memiliki tingkat pemahaman kognitif yang berbeda-beda selama pelaksanaan pembelajaran secara daring. Kemampuan kognitif siswa selama pembelajaran daring sangat berbeda ketika siswa melaksanakan pembelajaran tatap muka. Terdapat pemahaman kognitif siswa yang tinggi, sedang dan rendah. Hal ini sejalan dengan teori Taksonomi Bloom ranah kognitif dari yang sederhana (mengetahui) sampai dengan yang lebih kompleks (mengevaluasi). Dari 6 tingkatan tersebut yaitu: mengingat, memahami, mengaplikasikan, menganalisis, mengevaluasi, dan menciptakan.

Tabel 2. Perbandingan Taksonomi Bloom dan Revisi Pada Ranah Kognitif

\begin{tabular}{l|l|l}
\hline Taksonomi Bloom & Revisi Taksonomi Bloom & Keterangan \\
\hline Pengetahuan & Mengingat & \multirow{2}{*}{ Low Order Thinking Skills } \\
\cline { 1 - 2 } Pemahaman & Memahami & \\
\hline Penerapan & Mengaplikasikan & \multirow{2}{*}{ High Order Thinking Skill } \\
\hline Analisis & Menganalisis & \\
\hline Sintesis & Mengevaluasi & \\
\hline Evaluasi & Mengkreasi & Sumber: Effendi (2017:74)
\end{tabular}

\section{SIMPULAN}

Berdasarkan hasil penelitian dan pembahasan mengenai "Analisis Pemahaman Kognitif Matematika Materi Operasi Hitung Pecahan Menggunakan Video Pembelajaran Matematika Sistem Daring di Kelas V Sekolah Dasar" yang dilakukan di SDN 34/I Teratai, dapat peneliti simpulkan bahwa: "Kemampuan kognitif siswa dalam pembelajaran daring menggunakan video pembelajaran matematika materi operasi hitung pecahan di kelas V B memiliki kemampuan yang berbedabeda, yaitu terdapat siswa yang memiliki pemahaman kognitif yang tinggi, hal ini dapat dilihat dari cara siswa dalam menyelesaikan tugas operasi hitung pecahan dengan tepat dan siswa tersebut mampu menjawab dan menjelaskan pertanyaan peneliti dengan baik dan benar. Untuk siswa yang pemahaman kognitif sedang masih kurang tepat dalam menyelesaikan tugas operasi hitung pecahan dan siswa tersebut kurang tepat menjawab dan menjelaskan pertanyaan dari peneliti. Sedangkan, untuk siswa yang pemahaman kognitif yang rendah tidak mampu menyelesaikan tugas operasi hitung 
pecahan dengan tepat, serta tidak mampu menjawab dan menjelaskan pertanyaan dari peneliti. Lingkungan sekitar juga sangat berpengaruh terhadap pelaksanaan pembelajaran secara daring, karena selama pembelajaran daring orangtua masih belum mampu memfasilitasi siswa selama belajar dirumah".

\section{DAFTAR RUJUKAN}

Althabany, T.I.B 2014. Mendesain Model Pembelajaran Inovatif, Progresif, dan Kontekstual. Jakarta: Kencana.

Amiruddin. 2016. Perencanaan Pembelajaran. Yogyakarta: Parana Ilmu.

Ariyana, I K. S. 2020. Perumusan tujuan pembelajaran dan soal materi pecahan berbasis pada tingkat dimensi pengetahuan dan dimensi proses kognitif. In Prosiding Mahasaraswati Seminar Nasional Pendidikan Matematika 2020 (pp. 22-36).

Bloom, B.S., Engelhart, M.D., Furst, E.J., Hill, W.H., dan Krathwohl, D.R. 1956. The Taxonomy of Educational Objectives The Classification of Educational Educational Goals, Handbook 1: Cognitive Domain. New York: David McKay.

Ginanjar, O., Sholahudin, A., \& Paulus, E. 2017. Analisis dan Desain Pengembangan Program Aplikasi DMS dengan Metodologi Scrum Framework.

Nuraeni, D., Uswatun, D.A., \& Nurasiah, I. 2020. Analisis Pemahaman Kognitif
Matematika Materi Sudut

Menggunakan Video

Pembelajaran Matematika

Sistem Daring di Kelas IV B

SDN Pintukisi. Pendas: Jurnal

Ilmiah Pendidikan Dasar, 5(1), 61-75.

Nurani, Najila Indah, Din Azwar Uswatun, and Luthfi Hamdani Maula. "Analisis Proses Pembelajaran Matematika Berbasis Daring Menggunakan Aplikasi Google Classroom Pada Masa Pandemi Covid19." Jurnal PGSD 6.1 2020: 5056.

Nurani, N. I., Uswatun, D. A., \& Maula, L. H. 2020. Analisis

Proses Pembelajaran

Matematika Berbasis Daring Menggunakan Aplikasi Google Classroom Pada Masa Pandemi Covid-19. Jurnal PGSD, 6 (1), 50-56

Purnama, G. 2020. Student Who Learning Using Whatsapp Group Media With Student Which Learning Using Google Classroom Media Pandemic Time Covid-19. Journal Of Educational Experts (JEE), 3(2), 69-73.

Ramlan, Effendi. 2017. Konsep Revisi Taksonomi Bloom dan Implementasinya pada Pembelajaran Matematika SMP. Jurnal Ilmiah Pendidikan Matematika. Vol.2, No 1, 25028391.

Rusman. 2015. Pembelajaran Tematik Terpadu. Jakarta: Rajawali Pers. 
Yantoro, Suci Hayati, Latifatul Ulya : Analisis Kemampuan ...

Rusman. 2018. Belajar dan Pembelajaran Berbasis Komputer. Bandung: Alfabeta.

Salsabila, V., Amalia, A. R., \& Malula, L. H. 2020. Analisis Pemahaman Konsep Matematika Menggunakan Media Video Pembelajaran Matematika di Kelas III C SDN Dewi Sartika CBM. Didakti: Jurnal Ilmiah PGSD STKIP Subang, 6 (1), 148-154.

Sari, F. P., Basri, I., \& Ratna, E. 2018. Korelasi Keterampilan Membaca Pemahaman Karangan Eksposisi Dengan Keterampilan Menulis Karangan Eksposisi. Pendidikan Bahasa Indonesia, 7(1), 117-124.

Satori, D., Komariah, A. 2014: 200201. Metode Penelitian Kualitatif. Bandung: Alfabeta. Sofyana, U.M., \& Kusuma, A. B. (2018). Upaya meningkatkan kemampuan penalaran matematis siswa menggunakan pembelajran generative pada kelas VII SMP Muhammasiyah Kaliwiro, Kontinu: Jurnal Penelitian Didaktik Mtematika, 2(1), 14-29.

Sugiyono, 2015. Metode Penelitian Pendidikan. Bandung: Alfabeta. Sugiyono,, 2017. Metode Penelitian Kuantitatif, Kualitatif, dan $R \& D$. Bandung: Alfabeta.
Susanto Ahmad, 2013. Teori Belajar \& Pembelajaran di Sekolah Dasar. Jakarta: Prenada Media Group.

Syarifah, L. L. 2017. Analisis Kemampuan Pemahaman Matematis pada mata kuliah pembelajaran matematika SMA II. JPPm (Jurnal Penelitian dan Pembelajaran Matematika), 10 (2).

Tim Guru. 2015. Buku Pintar Pasti Lulus Sekolah SD Kelas 6. Jakarta: Penerbit HB.

Ulfiyani, U. 2019. Konflik Sosial dan Politik Dalam Novel The President Karya Mohamad Sobary (Doctoral dissertation, Universitas Peradaban).

Umbara Uba. 2017. Psikologi Pembelajaran Matmatika. Yogyakarta: Budi Utama

Untoro, dkk. 2016. Buku Pintar Pelajaran SD/MI 5 in 1. Jakarta: Wahyu Media

Utami, Y.P., \& Cahyono, D. A. D. 2020. Studi At Home: Analisis Kesulitan Belajar Matematika Pada Proses Pembelajaran Daring. Jurnal Ilmiah Matematika Realitik, 1(1), 2026.

Wadini, Banurea. 2019. Pembelajaran Matematika Untuk Calon Guru MI/SD. Medan: Widya Puspita. 